\title{
Pyeloplasty in children: is there a difference in patients with or without crossing lower pole vessel?
}

\author{
Hans-Walter Hacker • Philipp Szavay • \\ Helmut Dittmann · Hans-P. Haber • \\ Joerg Fuchs
}

Accepted: 15 May 2009/Published online: 6 June 2009

(C) Springer-Verlag 2009

\begin{abstract}
Introduction Most of the children with hydronephrosis do not require any surgical intervention. However, in individual cases, irreversible loss of renal function can develop. Predictive criteria have been proven ineffective so far in determining in which children obstruction will lead to renal damage. The aim of our retrospective study was to determine the role of a crossing lower pole vessel (CV) in children undergoing pyeloplasty.

Materials and methods Between 1996 and 2003, 137 patients (age between 6 weeks and 16 years) with unilateral
\end{abstract}

H.-W. Hacker $(\bowtie) \cdot$ P. Szavay · J. Fuchs

Abteilung für Kinderchirurgie,

Universitaetsklinik für Kinder- und Jugendmedizin,

72076 Tübingen, Germany

e-mail: hanswalter.hacker@ksl.ch

P. Szavay

e-mail: philipp.szavay@med.uni-tuebingen.de

J. Fuchs

e-mail: joerg.fuchs@med.uni-tuebingen.de

\section{H. Dittmann}

Department of Nuclear Medicine,

Universitaetskliniksklinikum Tuebingen,

Hoppe-Seyler-Str.3, 72076 Tübingen, Germany

e-mail: Htdittma@med.uni-tuebingen.de

H.-P. Haber

Department of Pediatrics I,

Universitaetsklinik für Kinder- und Jugendmedizin,

Hoppe-Seyler-Str.3, 72076 Tübingen, Germany

e-mail: prhaber@med.uni-tuebingen.de

Present Address:

H.-W. Hacker

Kinderchirurgische Klinik, Kinderspital Luzern,

Chefarzt PD Dr. med. M.G. Schwoebel,

6000 Lucerne 16, Switzerland ureteropelvic junction obstruction and no associated urological pathologies underwent Anderson-Hynes dismembered pyeloplasty. A total of 112 patients were evaluated with complete data. One of the following criteria was considered to be indication for surgery in children with grade 4 hydronephrosis: differential renal function (DRF) $<40 \%$; clinical symptoms such as pyolenephritis and flank pain; during follow-up renographies, a reduction of DRF $>10 \%$ and washout patterns II or III $b$ according to O'Reilly. We looked at the age during surgery and the kind of presentation. DRF was measured using diuretic renography preoperatively and 1 year postoperatively. A postoperative change in DRF of group A (children without $\mathrm{CV}, n=84$ ) was compared to that in group B (children with $\mathrm{CV}, n=28$ ).

Results Median age at the time of surgery was 5 months in group A compared to 23 months in group B. Only in $21.4 \%$ of the children with CV compared to $60.7 \%$ without $\mathrm{CV}$ hydronephrosis was diagnosed by ultrasound examination antenatally. We found a preoperative DRF of $42.4 \% \pm 11.2 \mathrm{SD}$ in group $\mathrm{A}$, and of $38.9 \% \pm 11.7 \mathrm{SD}$ in group B. The percentage of postoperative improvement was $3.3 \%$ in group A and $15.4 \%$ in group B.

Conclusions Children with ureteropelvic junction obstruction and $\mathrm{CV}$ received a delayed surgical treatment and showed a greater reduction in differential renal function preoperatively, in contrast to patients without CV. Our data show that $\mathrm{CV}$ is a risk factor for deterioration of renal function in children with hydronephrosis and we advocate for an early pyeloplasty in these children, especially if they have a high-grade dilatation and equivocal washout patterns in diuretic renographies. Further prospective studies are necessary in order to understand the natural history of $\mathrm{CV}$ and to reveal the importance of the crossing lower pole vessel as a structural anomaly lacking maturation. 
Keywords Hydronephrosis - Crossing vessel . Pyeloplasty · Outcome

$\begin{array}{ll}\text { Abbreviations } \\ \text { UPJ } & \text { Ureteropelvic junction } \\ \text { DRF } & \text { Differential renal function } \\ \text { DRG } & \text { Diuretic renography } \\ \text { CV } & \text { Crossing vessel } \\ \text { US } & \text { Ultrasound scanning } \\ \text { VCUG } & \text { Voiding cystourethrography }\end{array}$

\section{Introduction}

Ureteropelvic junction (UPJ) obstruction is caused by either intrinsic or extrinsic factors. Extrinsic stenosis is associated with crossing vessel, adhesions or kinking of the ureter at the UPJ. Literature stresses the benign nature of hydronephrosis in early childhood. Newborns and infants are especially likely (up to $90 \%$ ) to receive conservative therapy [1-4]. On the other hand, one can find literature that focuses on the possibility of an irreversible loss of function without adequate means to predict in which cases such a loss might occur [5].

Today differential renal function and clinical symptoms, rather than morphological and drainage criteria, are used as indicators for surgical intervention [2, 3, 6]. Until now, predictive parameters, employed earlier, have failed to indicate when renal damage due to obstruction might take place [1, 2, 6]. Josephson [6] describes this situation as urgently requiring further research. Neither the extent of the dilation as indicated in the ultrasound scanning (US) nor the renogram curve pattern categories according to O'Reilly, nor clinical symptoms can be considered to be reliable indicators for the likelihood of later decrease in function [2, $6,7]$. The aim of our retrospective study was to determine the role of a crossing lower pole vessel (CV) as an important cause for an extrinsic stenosis in hydronephrosis.

\section{Patients and methods}

We reviewed the records of 137 children with unilateral UPJ obstruction who underwent surgical correction at our institution from 1996 to 2003. Diagnoses revealed in 50\% prenatally recognized pyelectasis, in $42.9 \%$ pyelonephritits and flank pain, whereas $7.1 \%$ of the cases had been discovered by chance after the neonatal period. In some children, initial diagnostic procedures were performed elsewhere and three of them showed a significant loss of function preoperatively averaging $67 \%$ (from 45 to $90 \%$ ). All three had a grade 2-3 hydronephrosis with a CV in the initial US. Treatment at our institution followed a standard regime. Gray-scale and color Doppler sonographic imaging was performed in all patients using a $7 \mathrm{MHz}$ sector array tranducer (Sonoline Elegra Advanced Scanner; Siemens Medical Systems, Iselin, NJ, USA). In infants with dilatation of the pelvicalyceal system grade $2-4$ according to the criteria of the Society of Fetal Urology [8], we proceeded with diuretic renography (DRG). The mode of presentation in the elder children were urinary tract infection, flank pain or incidental finding on US. In the DRG, hydratation was started with intravenous $0.9 \% \mathrm{NaCl}$ solution $2 \mathrm{~h}$ before the examination $(20 \mathrm{ml} / \mathrm{kg}$ body weight and hour). We used technetium-99 m-MAG3 (1 MBq/kg body weight, minimal dose $10 \mathrm{MBq}$ ), and furosemide ( $0.5 \mathrm{mg} / \mathrm{kg}$ body weight) was administered after the renogram phase (20-30 min). Indication for surgery were one of the following criteria: reduced DRF $<40 \%$, reduction of DRF in follow-up renography $>10 \%$, clinical features such as pyelonephritis or flank pain and a curve type II or III b according to O'Reilly [9] during follow-up renographies. Obstruction in the curve type III b was defined as persistence of more than $50 \%$ of the maximal activity 20 min after injection of furosemide. US of all children receiving surgery revealed a grade 4 dilatation according to the system of the SFU (Society of Fetal Urology) at the time of pyeloplasty. Voiding cystourethrography (VCUG) was performed to rule out vesico-ureteral reflux only in children with a dilated ureter or with bilateral hydronephrosis. After exclusion of patients with bilateral hydronephrosis, associated urological pathologies or incomplete data, we evaluated 112 children in this retrospective study. As much as 102 patients received open and 10 received laparoscopic Anderson-Hynes dismembered pyeloplasty. Postoperatively, at 3 and 12 months, a DRG was carried out. In the evaluation, the DRF of the renography is compared preoperatively and 1 year postoperatively. The group of patients undergoing pyeloplasty was divided into group A (without CV) and group B (with CV). The decision whether there is a crossing lower pole vessel or not was made during surgery. For statistical evaluation we used the Student's $t$ test.

\section{Results}

There were 32 girls and 80 boys from the 112 evaluated patients with unilateral UPJ obstruction and complete data. Pyeloplasty was performed in 37 cases on the right, and in 75 cases on the left side. In $28(25 \%)$ children undergoing surgery, a crossing lower pole vessel was found to be the cause of the pelviureteric junction obstruction. This could be detected preoperatively by color Doppler ultrasound [10] in 25 of the 28 cases (Fig. 1). In group A (without 


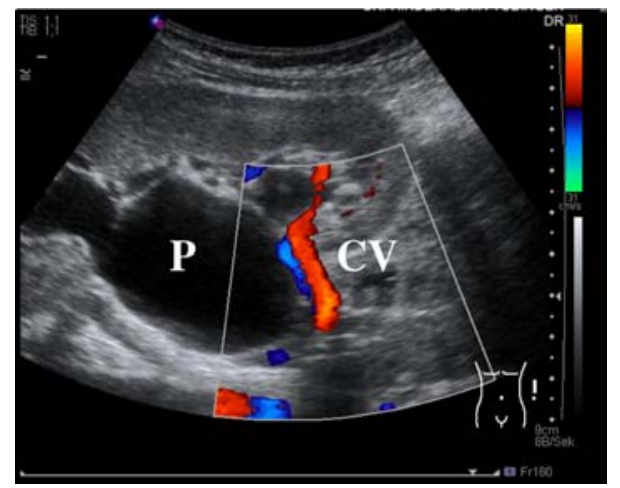

Fig. 1 Color Doppler ultrasound ( $P$ renal pelvis, $C V$ crossing vessel)

CV), $51(60.7 \%)$ children were detected by ultrasound examination antenatally, $24(28.6 \%)$ by clinical signs such as pyelonephritis (12 patients) or flank pain after birth (12 patients), and $9(10.7 \%)$ by chance beyond the neonatal period. In group B (with CV), 6 (21.4\%) children were diagnosed by ultrasound examination antenatally, 22 (78.6\%) by clinical signs after birth, and nobody by chance beyond the neonatal period (Fig. 2). In these 22 patients with $\mathrm{CV}$, pyelonephritis in 7 and flank pain in 15 led to the diagnosis. Median age at the time of surgery was 8 months (6 weeks-16 years) in the overall patients and 5 months in group A compared to 23 months in group B. Two children needed a temporary drug therapy because of hypertension.

Preoperatively, we found an average DRF of $41.5 \%$ $(\mathrm{SD} \pm 11.3)$ in the whole group, $42.4 \%(\mathrm{SD} \pm 11.2)$ in group $\mathrm{A}$, and $38.9 \%$ (SD \pm 11.7 ) in group $\mathrm{B}$ (Fig. 3). One year after surgery, the average DRF of all patients receiving pyeloplasty was $43.8 \%$ ( $\mathrm{SD} \pm 10.4$ ), whereas in group A it was $43.8 \%(\mathrm{SD} \pm 10.3)$ and in group B $44.9 \%$ ( $\mathrm{SD} \pm 10.6)$. For all patients undergoing pyeloplasty $(n=112)$, an increase in DRF of $5.6 \%(P<0.057)$ was observed 1 year postoperatively. The percentage of improvement was $3.3 \%$ (no significance) in group A and $15.4 \%(P<0.025)$ in group B. Patients from both groups $\mathrm{A}$ and $\mathrm{B}$ in whom the hydronephrosis was found by chance after birth $(n=9)$, showed an average improvement

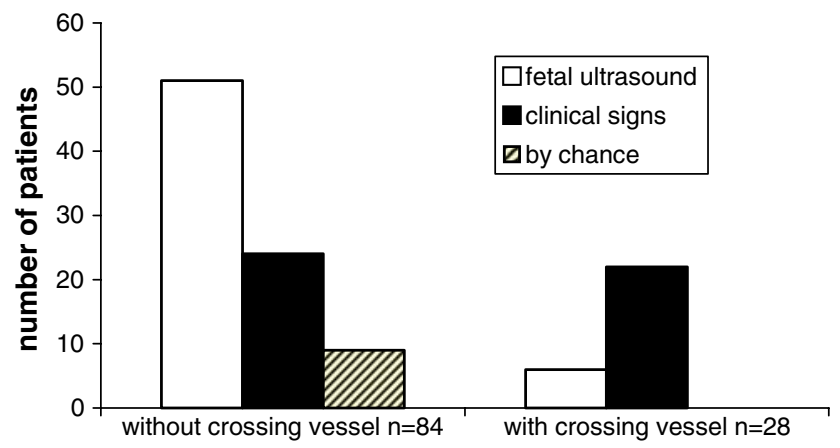

Fig. 2 Diagnosis of hydronephrosis

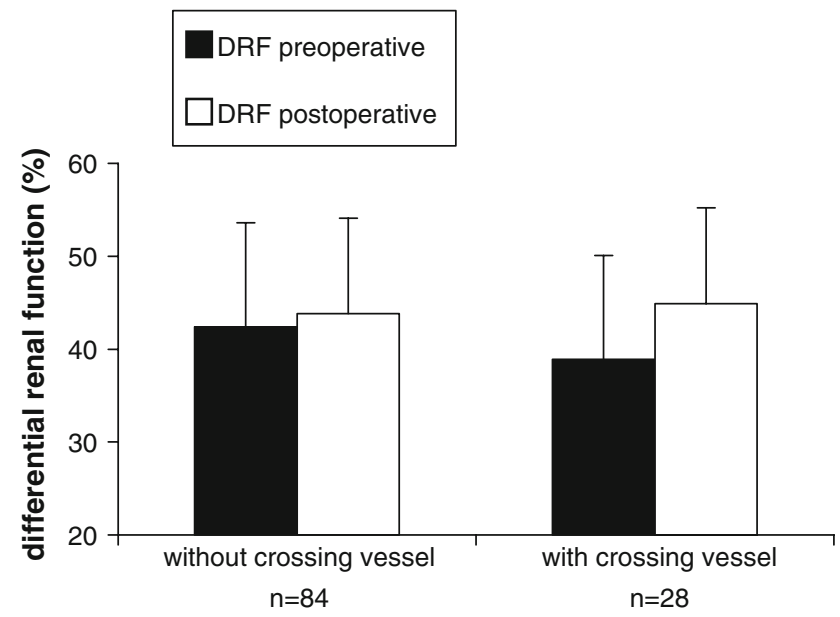

Fig. 3 Change in DRF 1 year after pyeloplasty

in DRF from $38.8 \%(\mathrm{SD} \pm 11.4)$ preoperatively to $45.1 \%$ ( $\mathrm{SD} \pm 8.3$ ) postoperatively. This is an improvement in renal function of approximately $16 \%, 1$ year after pyeloplasty.

Three patients showed a curve type II according to O'Reilly in the renal scan 3 months after surgery. Although there was no important decrease in renal function but an extensive dilatation in the US, we decided to re-operate on these patients. Another three patients with unilateral hydronephrosis and a crossing lower pole vessel were observed to have a significant loss of function preoperatively averaging $67 \%$ (from 45 to $90 \%$ ), with only marginal improvement postoperatively (Fig. 4). The children remained clinically completely unremarkable on repeat US during the preoperative observation phase lasting for at least 2 years.

\section{Discussion}

In our department, infants with high-grade hydronephrosis are treated conservatively when they are without clinical symptoms and have equal function in both kidneys, even

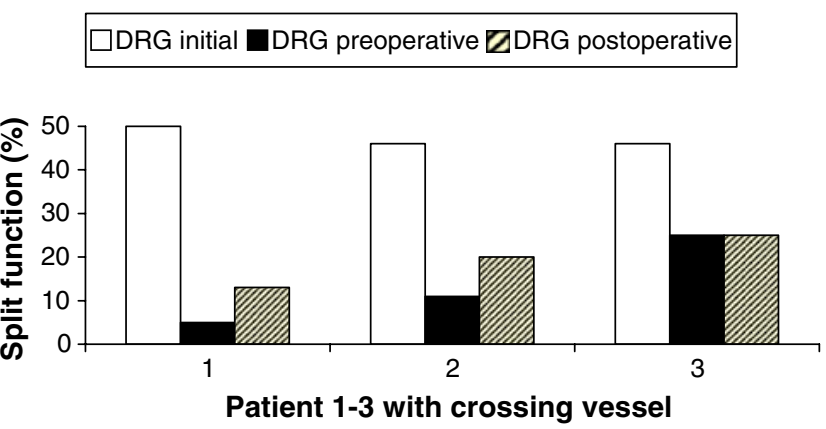

Fig. 4 Loss of function during observation 
when we find a type 2 or 3 b renogram curve (O'Reilly 1978). Observation of children with hydronephrosis is performed according to Dhillon's [11] suggested management procedures. She advised that patients with a pelvic diameter between 13 and $19 \mathrm{~mm}$ should have a follow-up by US including isotope studies at 3 months, 1 year and if possible at 2, 5 and 10 years. Children with hydronephrosis of more than $20 \mathrm{~mm}$ require close follow-up with US and renal scans at 1, 3 and 6 months, 1 year and annually thereafter. Our indications for surgery were in accordance with clearly defined parameters in renography and in compliance with published standards [12] as mentioned above. Patients with UPJ obstruction caused by a crossing vessel were discovered in $78.6 \%$ because of clinical complaints such as pyelonephritis or flank pain. These patients had mostly intermittent symptoms and the age at surgery was therefore much higher (median 23 months vs. 5 months) than in the group without CV. Also the differential renal function had declined much more and function postoperatively improved, but could not completely be restored (Fig. 3).

To date, controversy continues on indication and timing of pyeloplasty in infants with hydronephrosis. Along with maturation of hydronephrosis in early childhood, a permanent loss of function can also develop, not only when there is a lack of compliance [2, 3, 13-15]. Dhillon [11] reported these findings in 4 of 14 children who originally had good DRF, but did not recover after surgical correction. Thorup [16] mentions that $5 \%$ of the children observed show a decrease in function even with intensive follow-up. Boubaker [17] found in his series a normalization of function postoperatively only with intervention during the first year of life. Palmer [15] reported that 25\% of the observed children later required surgery and that the likelihood of restored function from the surgical intervention was greatest within the first 6 months.

Initially, the established imaging procedures can reveal an equal DRF on both sides and lack of signs of obstruction in the washout curves. A decrease in function is not always accompanied by an increase in dilatation that can be detected on ultrasound examination $[2,6]$. Also, the renogram curve pattern categories according to O'Reilly, and clinical symptoms, cannot be considered as reliable indicators for the likelihood of later decrease in function [2, 6]. This statement is supported by our data. Children, whose UPJ obstruction was discovered postnatally by chance, had lower DRF preoperatively when compared with the whole group. Also Capolicchio [5] reported on patients with incidental finding of hydronephrosis on US who had a mean DRF of $26 \%$ preoperatively, whereas children with urinary tract infection or flank pain showed an initial DRF of about $40 \%$.
Mild prenatal hydronephrosis $(<15 \mathrm{~mm})$ does not exclude a symptomatic and severe obstruction later on [18]. Three of our patients with unilateral grade 2-3 hydronephrosis and a crossing lower pole vessel were observed to have a significant loss of function preoperatively averaging $67 \%$, with only marginal improvement after pyeloplasty (Fig. 4). All three received treatment before surgery elsewhere and remained clinically completely unremarkable on repeat US during the observation phase lasting at least 2 years. Not included in our study are three patients with a unilateral UPJ obstruction and a DRF $<10 \%$, undergoing primary nephrectomy at the same period from 1996 to 2003. Two infants had an intrinsic stenosis and the third one was a 13 -year-old boy with $\mathrm{CV}$, diagnosed by chance.

The crossing lower pole vessel in hydronephrosis is a structural anomaly without spontaneous maturation. Zeltscher [19] reports an incidence of $39-71 \%$ of CV in adults with obstructed UPJ, whereas the prevalence in childhood is much lower. Pinto found normal ureteral tissue in pathological specimen from laparoscopic pyeloplasties in adults, when the UPJ obstruction was associated with CV. In these patients, maturation cannot occur. In hydronephrosis without $\mathrm{CV}$, a much higher frequency of fibrosis, smooth muscle hypertrophy, chronic inflammation and smooth muscle atrophy could be demonstrated in the ureteral tissue [20]. Here, we can observe spontaneous maturation in infants and young children. While literature contains many studies which detail the small risk of deteriorating renal function in neonatal patients with hydronephrosis [1-4], our data show that the subgroup with aberrant lower pole vessel has proven to be at an increased risk.

Since this retrospective study was limited to patients undergoing pyeloplasty, we focused only on children with $\mathrm{CV}$ associated with grade 4 hydronephrosis. Further prospective studies are necessary in order to reveal the importance of the crossing lower pole vessel as a significant cause for UPJ obstruction and to understand the natural history of CV. With the color Doppler ultrasonography, we have an excellent diagnostic tool to recognize a crossing vessel in children with hydronephrosis. Veyrac [10] reported on a sensitivity of $92.8 \%$ by this method. Children undergoing different kinds of therapy have to be focused on, including those undergoing nephrectomy, as well as those who underwent long-term conservative treatment. This may lead to include the diagnosis of an aberrant lower pole vessel as additional criteria into already established indications for surgery in case of high-grade hydronephrosis, especially in children with equivocal diuretic renograms and intermittent obstruction. 


\section{References}

1. Koff SA, Campbell KD (1994) The nonoperative management of unilateral neonatal hydronephrosis: natural history of poorly functioning kidneys. J Urol 152:593-595

2. Freedman ER, Rickwood AMK (1994) Prenatally diagnosed pelviureteric junction obstruction: a benign condition? J Pediatr Surg 29:769-772

3. Ransley PH, Dhillon HK, Gordon I, Duffy PG, Dillon MJ, Barratt TM (1990) The postnatal management of hydronephrosis diagnosed by prenatal ultrasound. J Urol 144:584-587

4. Chertin B, Rolle U, Farkas A, Puri P (2002) Does delaying pyeloplasty affect renal function in children with a prenatal diagnosis of pelvi-ureteric junction obstruction? BJU Int 90:72-75

5. Capolicchio G, Leonard MP, Wong C, Jednak R, Brzezinski A, Pippi Salle JL (1999) Prenatal diagnosis of hydronephrosis: impact on renal function and its recovery after pyeloplasty. J Urol 162:1029-1032

6. Josephson J (2002) Antenatally detected, unilateral dilation of the renal pelvis: a critical review. 2. Postnatal non-operative treatment-long-term hazards, urgent research. Scand J Urol Nephrol 36:251-259

7. Homsy YL, Saad F, Laberge I, Williot P, Pison C (1990) Transitional hydronephrosis of the newborn and infant. J Urol 144:579-583

8. Maizels M, Reisman ME, Flom LS, Nelson J, Fernbach S, Firlit CF, Conway JJ (1992) Grading nephroureteral dilatation detected in the first year of life: correlation with obstruction. J Urol 148:609

9. O'Reilly PH, Testa HJ, Lawson RS et al (1978) Diuresis renography in equivocal urinary tract obstruction. $\mathrm{Br} \mathrm{J}$ Urol 50:76-80

10. Veyrac C, Baud C, Lopez C, Couture A, Saguintaah M, Averous M (2003) The value of colour Doppler ultrasonography for identification of crossing vessels in children with pelviureteric junction obstruction. Pediatr Radiol 33:745-751

11. Dhillon HK (1998) Prenatally diagnosed hydronephrosis: the Great Ormond Street experience. Br J Urol 81:39-44

12. Riccabona M (2004) Assessment and management of newborn hydronephrosis. World J Urol 22:73-78

13. Chertin B, Fridmans A, Knizhnik M, Hadas-Halperin I, Hain D, Farkas A (1999) Does early detection of ureteropelvic junction obstruction improve surgical outcome in terms renal function? J Urol 162:1037-1040

14. Eskild-Jensen A, Munch Jorgensen T, Olsen LH, Djurhuus JC, Frok J (2003) Renal function may not be restored when using decreasing differential function as the criterion for surgery in unilateral hydronephrosis. BJU Int 92:779-782

15. Palmer LS, Maizels M, Cartwright PC, Fernbach SK, Conway JJ (1998) Surgery versus observation for managing obstructive grade 3 to 4 unilateral hydronephrosis: a report from the Society of Fetal Urology. J Urol 159:222-228

16. Thorup J, Jokela R, Cortes D, Nielsen OH (2003) The results of 15 years of consistent strategy in treatment antenatally suspected pelvi-ureteric junction obstruction. BJU Int 91:850-852

17. Boubaker A, Meyrat B, Frey P, Bischof Delaloye A (2003) Unilateral urinary flow impairment at the pelviureteral junction: outcome of renal function with respect to therapeutic strategy. Urology 61:1224-1228

18. Rigas A, Karamanolakis D, Bogdanos I, Stefanidis A, Androulakakis PA (2003) Pelvi-ureteric junction obstruction by crossing renal vessels: clinical and imaging features. BJI Int 92:101-103

19. Zeltscher IS, Liu JB, Bagley DH (2004) The incidence of crossing vessels in patients with normal ureteropelvic junction examined with endoluminal ultrasound. J Urol 172:2304-2307

20. Pinto PA, Bluebond-Langner R, Trock B, Jarett TW, Kavoussi LR (2003) Pathologic correlation between ureteropelvic junction obstruction and crossings vessels. J Urol 169:24 abstract 94 